\title{
EVALUATION OF THE STRONG GROUND MOTIONS IN THE AREA CLOSE TO THE SURFACE FAULTS
}

\author{
Kiyoshi Irie ${ }^{1}$, Kazuo Dan ${ }^{1}$, Ryoichiro Matsumoto ${ }^{2}$, and Haruhiko Torita ${ }^{1}$ \\ ${ }^{1}$ Ohsaki Research Institute, Inc., Dr. Eng., Japan \\ ${ }^{2}$ Ohsaki Research Institute, Inc., Japan
}

\section{ABSTRACT}

In Japan, the seismic waves radiated from the shallow soil above the seismogenic zone are not considered in the usual strong motion prediction. However, in the inland crustal earthquakes, the strong ground motions in the area close to the surface faults could be influenced by the seismic waves radiated from the shallow soil. Hence, we evaluated the seismic waves radiated from the shallow soil as for a vertical strike-slip fault, to investigate its influence on the strong motions. We synthesized seismic waves by the wave-number integration technique (Hisada, 1994), using the slip-velocity time functions obtained in the dynamic fault rupturing simulation of the three-dimensional finite difference method (Pitarka et al., 2005). The used dynamic fault rupturing model was $25 \mathrm{~km}$ in length and $18 \mathrm{~km}$ in width, with the shallow soil of 3-km thickness and the slip-weakening law, that agreed with the empirical relationship among the fault parameters of Matsuda (1975), Irikura and Miyake (2001) and Dan et al. (2001). As the results, in the area close to the surface fault trace, the seismic waves of the fault normal component were larger than those of the fault parallel component in the period range of 0.5 to 3 seconds. And, at least, $90 \%$ of the fault normal component close to the surface fault trace was attributed to the seismic wave radiated from the seismogenic zone. And, almost $100 \%$ of the fault parallel component close to the surface fault trace was attributed to the seismic wave radiated from the shallow soil.

\section{INTRODUCTION}

The strong motion pulses which brought the band of the earthquake disaster of seismic intensity 7 in Kobe, Japan, earthquake, 1995, were radiated from asperities (Matsushima and Kawase, 2006). Since then, the asperity model, which consists of the asperity areas and the background area, has been the most popular fault model in Japan for predicting strong ground motions.

In the asperity models, the source fault is set in the seismogenic layer (Ito, 1999; Scholz, 2002) as shown in Figure 1, and it's supposed that most seismic waves are radiated from the source fault. This means ignoring the seismic wave radiated from the shallower layers than the seismogenic layer.

But, in recent years, it's pointed out that active faults might exist very close to nuclear power plants. And in these cases, even if the seismic wave radiated from the shallow soil is a little, it is thought that the seismic wave radiated from the shallow soil might influence the safety of the facilities a lot (Nuclear Regulation Authority, 2013).

Hence, in this study, we estimated the seismic wave radiated from the shallow soil in the strike-slip fault, and we compared the result with the seismic wave radiated from the entire fault.

First, we built a dynamic fault rupturing model under the constraints by empirical relationships among fault parameters of the surface and subsurface faults. Next, we synthesized seismic waves by the wave number integration technique using slip-velocity time functions obtained as a result of the dynamic fault rupturing simulation. As the case 1, we synthesized the seismic wave by using slip-velocity time functions on the entire fault. As the case 2, we synthesized the seismic wave by using slip-velocity time functions only on the fault in the seismogenic layer. And as the case 3, we synthesized the seismic wave by using slip-velocity time functions only on the fault in the shallower soil than the seismogenic layer. Finally, we compared the results of these cases and estimated the percentage of the seismic wave radiated 


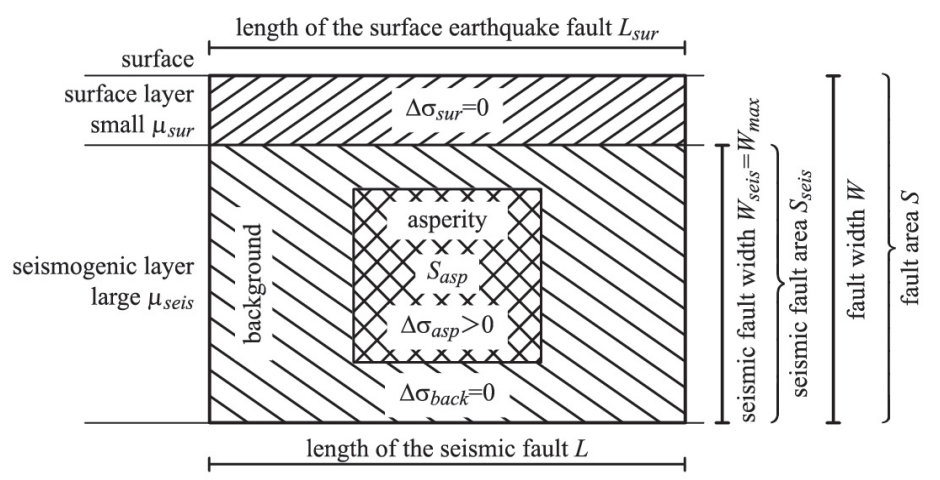

Figure 1. Image of the ruptured area and the seismic fault in an earthquake.

from the shallow soil to that from the seismogenic layer.

\section{DYNAMIC FAULT RUPTURING MODEL}

When we estimate the maximum displacement of the surface fault for the event caused by the active fault, we use the empirical relationship between the fault length $L_{s u r}$ and the magnitude $M$ and that between and the displacement of the fault trace $D_{s u r}$ and the magnitude $M$. These relationships were proposed by Matsuda (1975).

On the other hand, when we estimate the average slip of the entire seismic source fault for strong motion prediction, we use the empirical relationship between the fault area $S$ and the seismic moment $M_{0}$ proposed by Somerville et al. (1999) for smaller earthquakes as the subsurface-fault events and that proposed by Irikura and Miyake (2001) for larger earthquakes as the surface-fault events.

Therefore, the maximum displacement amount of the surface fault and the average slip amount of the entire seismic fault are calculated independently. But the displacement of the surface fault is a physical result of the seismic fault. So, we thought that the maximum displacement amount of the surface fault and the average slip amount of the entire seismic fault should be expressed in the identical physical model.

The empirical relationship by Matsuda (1975) is equation (1), relating $D_{\text {sur }}$ and $L_{\text {sur }}$. Figure 2 shows equation (1) and the data by Matsuda (1975). The data include the values obtained from seismological or geodetic data as well as the values of surface faulting. We used equation (1) as one of the constraints for the dynamic fault rupturing model.

$$
D_{\text {sur }}[\mathrm{m}]=0.0794 L_{\text {sur }}[\mathrm{km}]
$$

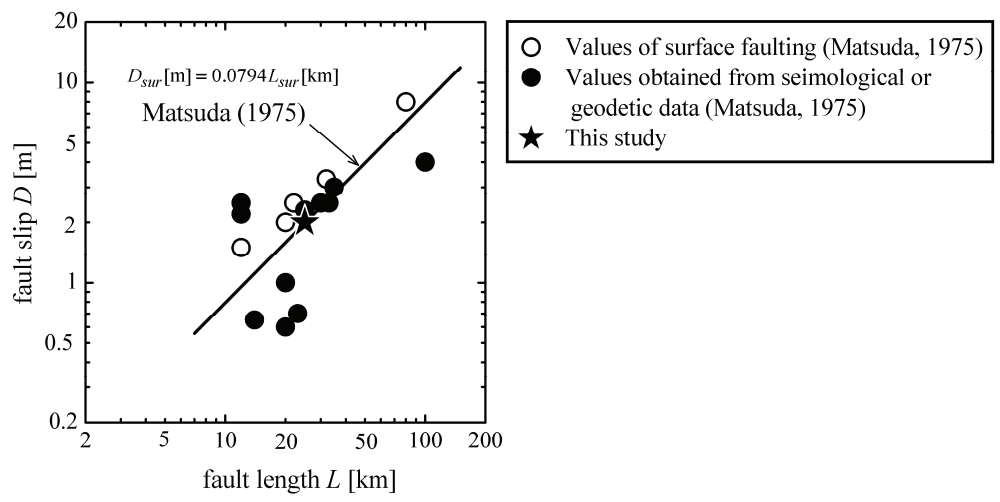

Figure 2. The relationship between the fault length $L$ and the fault slip $D$. 
Figure 3 shows the empirical relationships between the fault area $S$ and the seismic moment $M_{0}$ by Somerville et al. (1999) and Irikura and Miyake (2001), and the data by Somerville et al. (1999) and Stirling et al. (2002). We used equation (2) of the empirical relationship by Irikura and Miyake (2001) as one of the constraints for the dynamic fault rupturing model, because our target is a large earthquake.

$$
S\left[\mathrm{~km}^{2}\right]=4.24 \times 10^{-11} \times\left(M_{0}[\text { dyne } \bullet \mathrm{cm}]\right)^{1 / 2}
$$

Figure 4 shows the empirical relationship between the short-period level $A$ and the seismic moment $M_{0}$ by Dan et al. (2001) and the data by Dan et al. (2001). The short-period level is the flat level of the acceleration source spectrum in short period domain. For the strong motion prediction, we estimate the short-period level $A$ from the seismic moment $M_{0}$ by the empirical relationship of equation (3) proposed by Dan et al. (2001). When we used equation (3) as one of the constraints for a dynamic fault rupturing model, the peak ground velocity (PGV) obtained in the dynamic rupturing simulation was overestimated compared to the attenuation equation by Si and Midorikawa (1999). Then we used equation (4) which was the half $A$ of equation (3) as one of the constraints for the dynamic fault rupturing model.

$$
\begin{gathered}
A\left[\text { dyne } \bullet \mathrm{cm} / \mathrm{s}^{2}\right]=2.46 \times 10^{17} \times\left(M_{0}[\text { dyne } \bullet \mathrm{cm}]\right)^{1 / 3} \\
A^{\prime}\left[\text { dyne } \bullet \mathrm{cm} / \mathrm{s}^{2}\right]=2.46 \times 10^{17} \times\left(M_{0}[\text { dyne } \bullet \mathrm{cm}]\right)^{1 / 3} / 2
\end{gathered}
$$

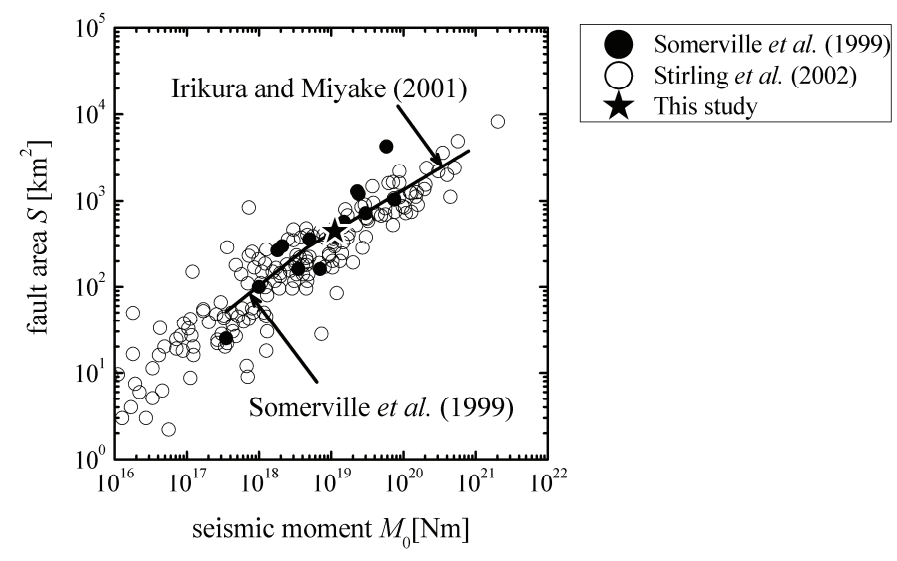

Figure 3. The relationship between the seismic moment $M_{0}$ and the fault area $S$.

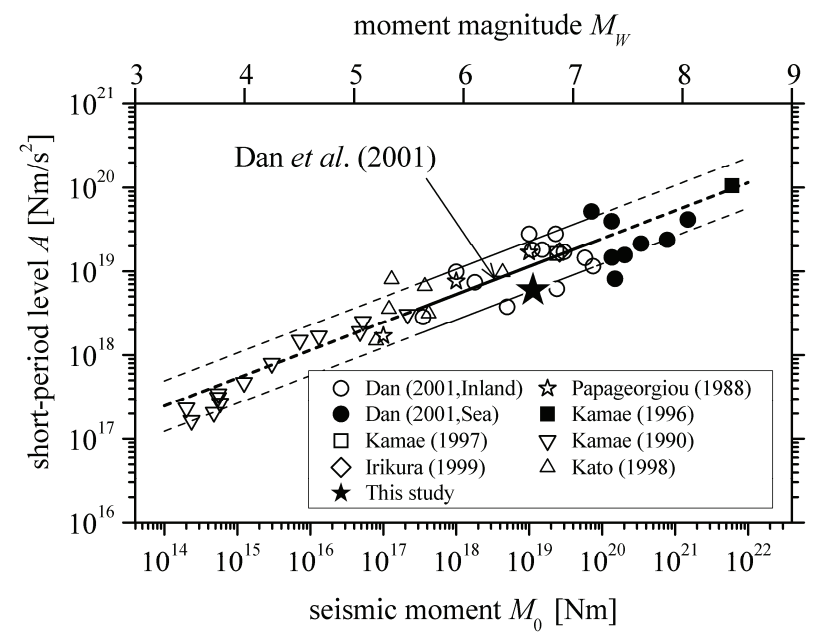

Figure 4. The relationship between the seismic moment $M_{0}$ and the short-period level $A$. 
Figure 5 shows the asperity model for the dynamic fault rupturing simulation. The fault length and the fault width are given apriori. It had two asperities, whose area ratio was 16:6 as derived by Somerville et al. (1999). The upper end of asperities was assumed to be $5 \mathrm{~km}$ deep based on the results by Kagawa et al. (2004). The area of the asperities and the dynamic stress drop on the asperities were obtained by the method of Irie et al. (2010) using the iteration of the dynamic rupturing simulation to make the dynamic fault model meet equations (2) and (4).

Table 1 shows the soil profile for the dynamic fault rupturing simulation. The layer No. 6 is the seismogenic layer and the values of the properties ( $P$-wave velocity $\alpha, S$-wave velocity $\beta$, and density $\rho$ ) are assumed apriori. The properties of the shallower layers (layer Nos. 1 to 5) were obtained by the method of Irie et al. (2010) using the iteration of the dynamic fault rupturing simulation to fit equation (1).

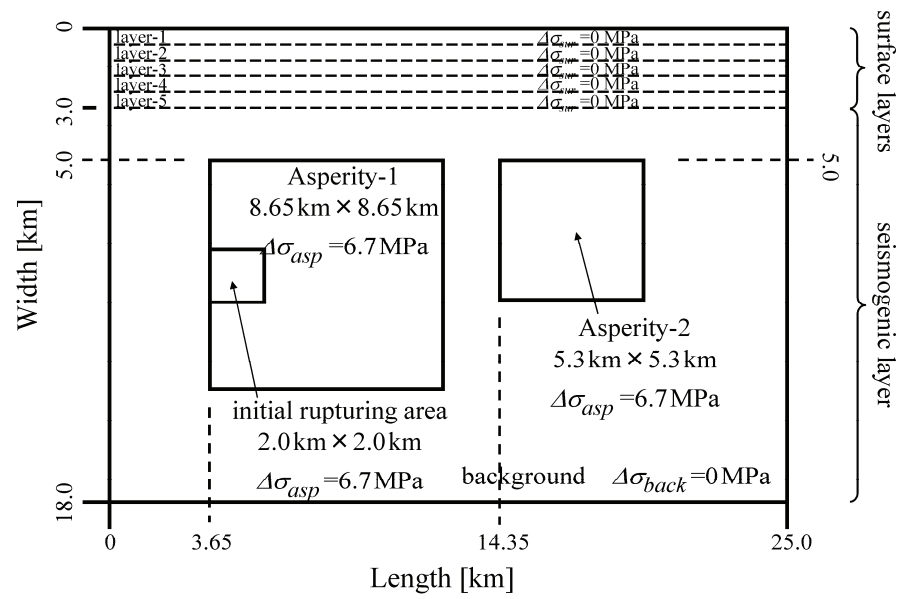

Figure 5. The asperity model for the dynamic fault rupturing simulation.

Table 1. The soil profile for the dynamic fault rupturing simulation.

\begin{tabular}{|c|c|c|c|c|c|c|}
\hline layer No. & $\begin{array}{c}\text { depth } \\
{[\mathrm{km}]}\end{array}$ & $\begin{array}{c}\text { thickness } \\
{[\mathrm{km}]}\end{array}$ & $\begin{array}{c}\alpha \\
{[\mathrm{km} / \mathrm{s}]}\end{array}$ & $\begin{array}{c}\beta \\
{[\mathrm{km} / \mathrm{s}]}\end{array}$ & $\begin{array}{c}\rho \\
{\left[\mathrm{t} / \mathrm{m}^{3}\right]}\end{array}$ & \multirow{2}{*}{ note } \\
\hline 1 & $0.0 \sim 0.6$ & 0.6 & 2.2 & 0.78 & 2.0 & \multirow{2}{*}{ surface } \\
\cline { 1 - 6 } 2 & $0.6 \sim 1.2$ & 0.6 & 2.8 & 1.32 & 2.2 & \multirow{2}{*}{ surface layers } \\
\hline 3 & $1.2 \sim 1.8$ & 0.6 & 3.6 & 1.87 & 2.4 & \\
\hline 4 & $1.8 \sim 2.4$ & 0.6 & 4.3 & 2.41 & 2.5 & \\
\cline { 1 - 5 } 5 & $2.4 \sim 3.0$ & 0.6 & 5.2 & 2.96 & 2.6 & \\
\hline 6 & $3.0 \sim$ & - & 6.0 & 3.50 & 2.7 & \multirow{2}{*}{ seismogenic layer } \\
\hline
\end{tabular}

Figure 6 shows the analysis model of the dynamic fault rupturing simulation. The fault is vertical left-lateral strike-sip type. The dynamic fault rupturing simulation was performed by the 3D finite difference method program (Pitarka and Dalguer, 2003; Pitarka, 2005; Pitarka et al., 2005), and the grid interval was set to $0.05 \mathrm{~km}$ to maintain the shortest effective period of about 0.5 seconds. Figure 7 shows the slip-weakening models used as the constitutional law on the fault. Here, we assumed the values of the dynamic stress drops of the shallow soil and the background to be $0 \mathrm{MPa}$. We assumed the values of the critical distance $D_{c}$ and the strength excess $S E$ apriori.

Figure 8 shows the examples of the slip-velocity time functions of the results by the dynamic fault rupturing simulation. Here, the slip-velocity time functions were calculated at all the grids on the fault every $0.05 \mathrm{~km}$. Figure 9 shows the distribution of the final slip calculated by integral of the slip-velocity time functions at each grid. From Figures 8 and 9, the areas of larger slip velocity and larger final slip are found to be on the two asperities and near the surface. 


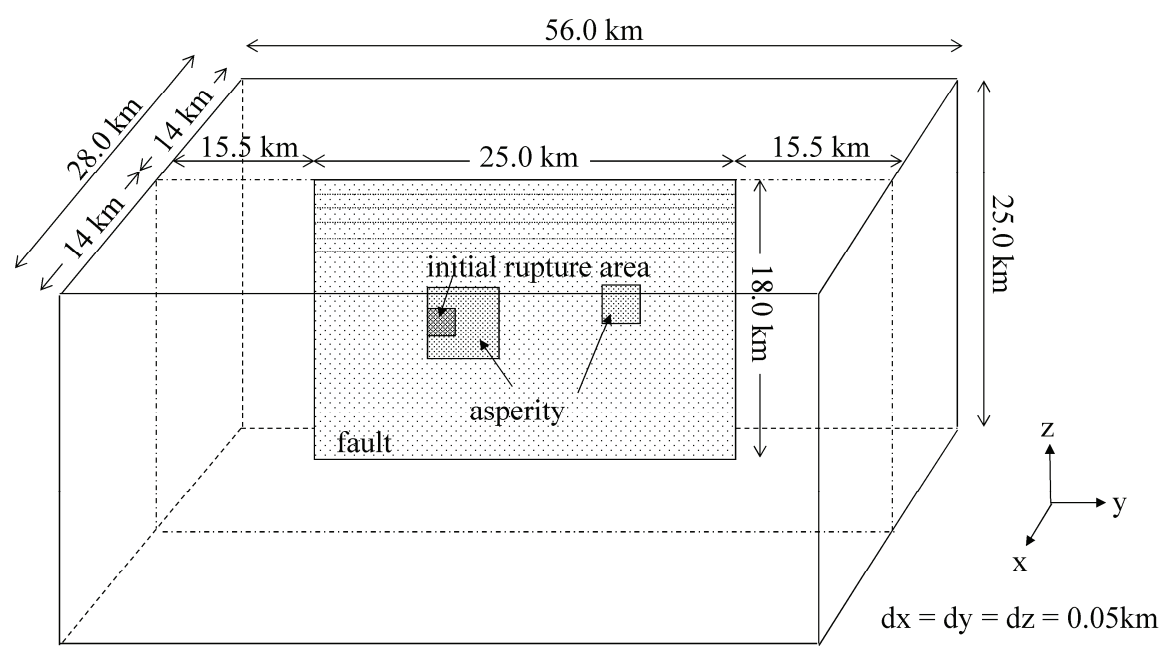

Figure 6. The analysis model of the dynamic fault rupturing simulation.

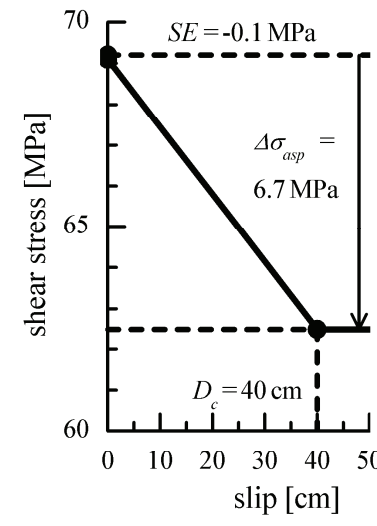

(a) initial rupturing area

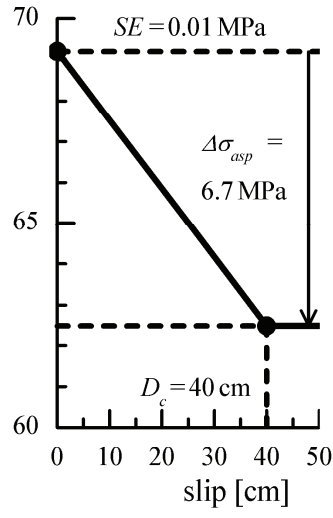

(b) asperity area

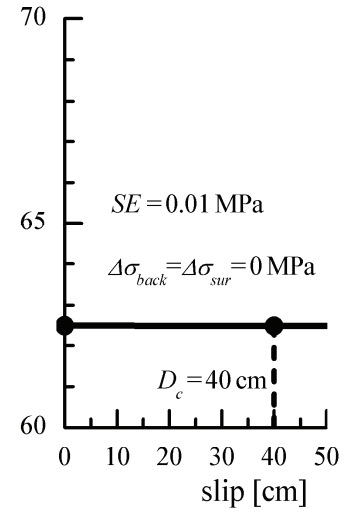

(c) backgound and surface layers

Figure 7. The slip-weakening models on the fault.

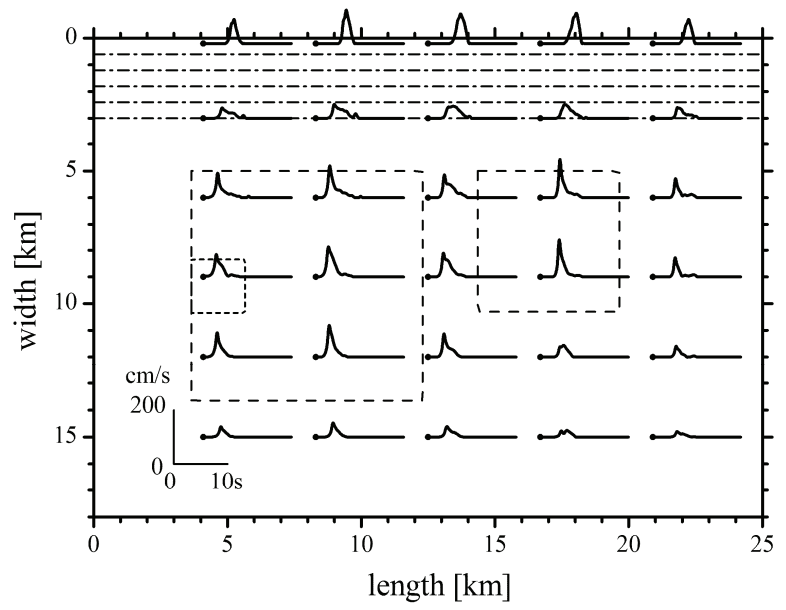

Figure 8 . The examples of slip-velocity time functions by dynamic fault rupturing simulation. 


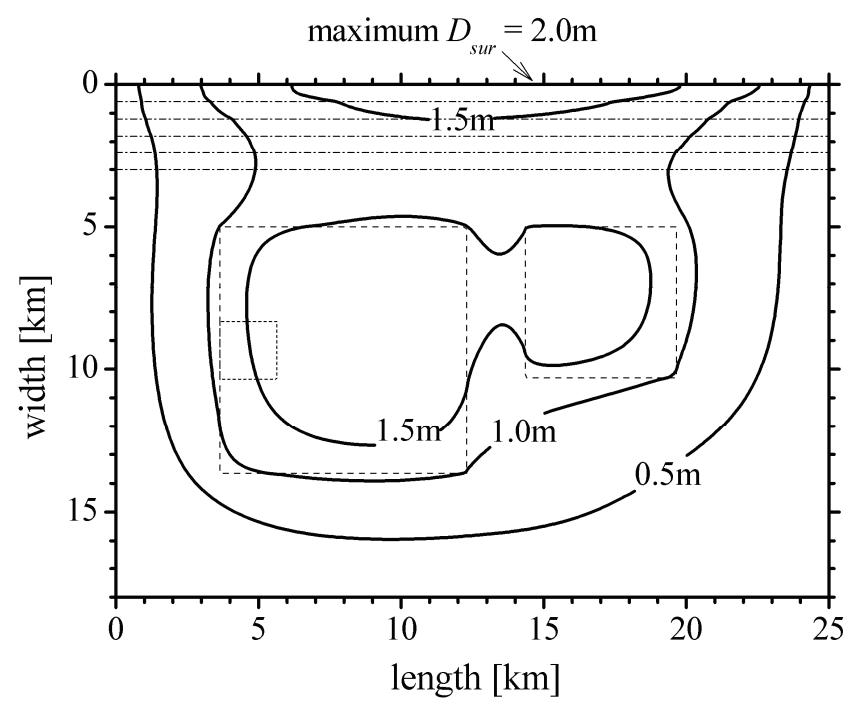

Figure 9. The distribution of the final slip by the dynamic fault rupturing simulations.

In Figure 2, the star is the relation between the fault length and the maximum slip on the surface fault trace by the dynamic simulation, and we find out that it's on the equation (1) by Matsuda (1975). In Figure 3, the star is the relation between the seismic moment and the fault area by the dynamic simulation, and we find out that it's on the equation (2) by Irikura and Miyake (2001). In Figure 4, the star is the relation between the seismic moment and the short-period level by the dynamic simulation, and we find out that it's on the equation (4). Therefore, the dynamic fault model in this study satisfies all the three constraints about the surface fault and the seismic fault.

The open circles in Figure 10 show the relationship between the shortest distance from the fault and the peak ground velocity (PGV) of the results by the dynamic fault rupturing simulation in this study. In Figure 10, the lines are the empirical attenuations (mean and mean \pm sigma) by Si and Midorikawa (1999). In this result, the PGV corresponds to the empirical attenuation very well.

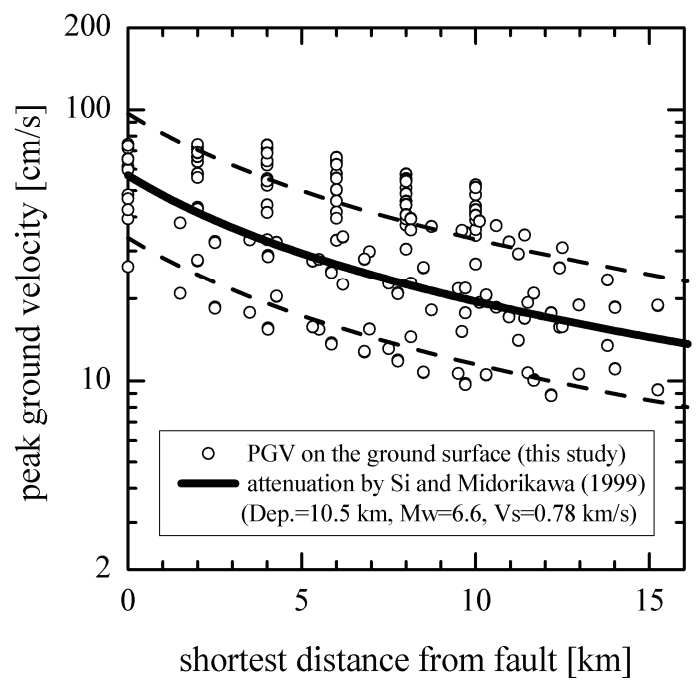

Figure 10. Comparison between the PGV of the results by the dynamic fault rupturing simulation and the attenuation by Si and Midorikawa (1999). 


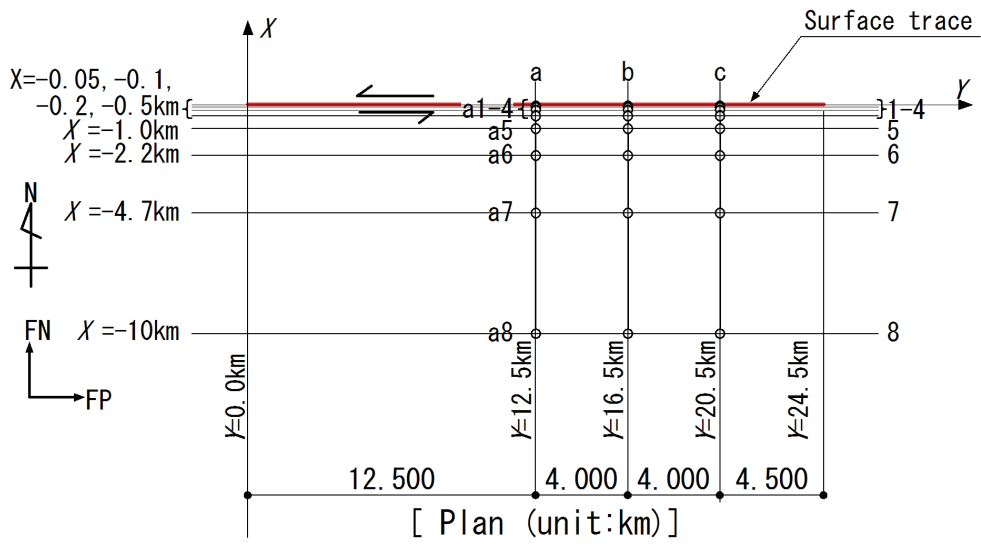

Figure 11. Points of ground motion synthesis.

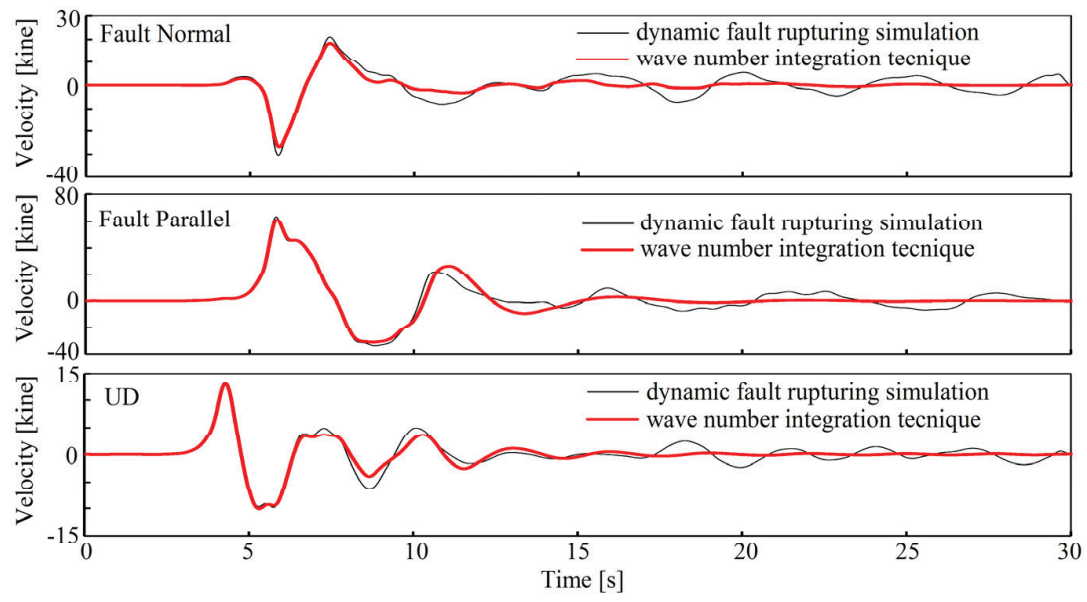

Figure 12. Comparison between the seismic waves by the dynamic fault rupturing simulation (black lines) and the seismic waves by the wave number integration technique (red lines) at the point a6 in Figure 11. The fault distance is $2.2 \mathrm{~km}$.

\section{QUANTITATIVE EVALUATION OF GROUND MOTIONS RADIATED FROM SHALLOWER SOIL}

In this study, as case 1, we synthesized ground motions by the wave number integration technique of Hisada (1994) using the slip-velocity time functions in Figure 8 obtained by the dynamic fault rupturing simulation.

Figure 11 shows points of synthesized velocity ground motions by the wave number integration technique. Here, the red line is the surface trace of the fault, and synthesis points are arranged densely near the surface trace. As away from the surface trace, synthesis points are assigned sparsely.

Figure 12 shows the comparison between the ground motions by the wave number integration technique at the point a6 (fault distance is $2.2 \mathrm{~km}$ ) in Figure 11 and those by the dynamic fault rupturing simulation near the point a6. Here, we confirmed that the main part of the velocity waves by the dynamic fault rupturing simulation could be reproduced by the wave number integration technique. However, the later phases of the velocity waves by the dynamic fault rupturing simulation were not reproduced because the movement of the whole analysis model in Figure 6 was not settled even after all the slip on the fault terminated. Moreover, in the wave number integration technique, we set $\mathrm{Q}$ values in 
$23^{\text {rd }}$ Conference on Structural Mechanics in Reactor Technology Manchester, United Kingdom - August 10-14, 2015

Division IV
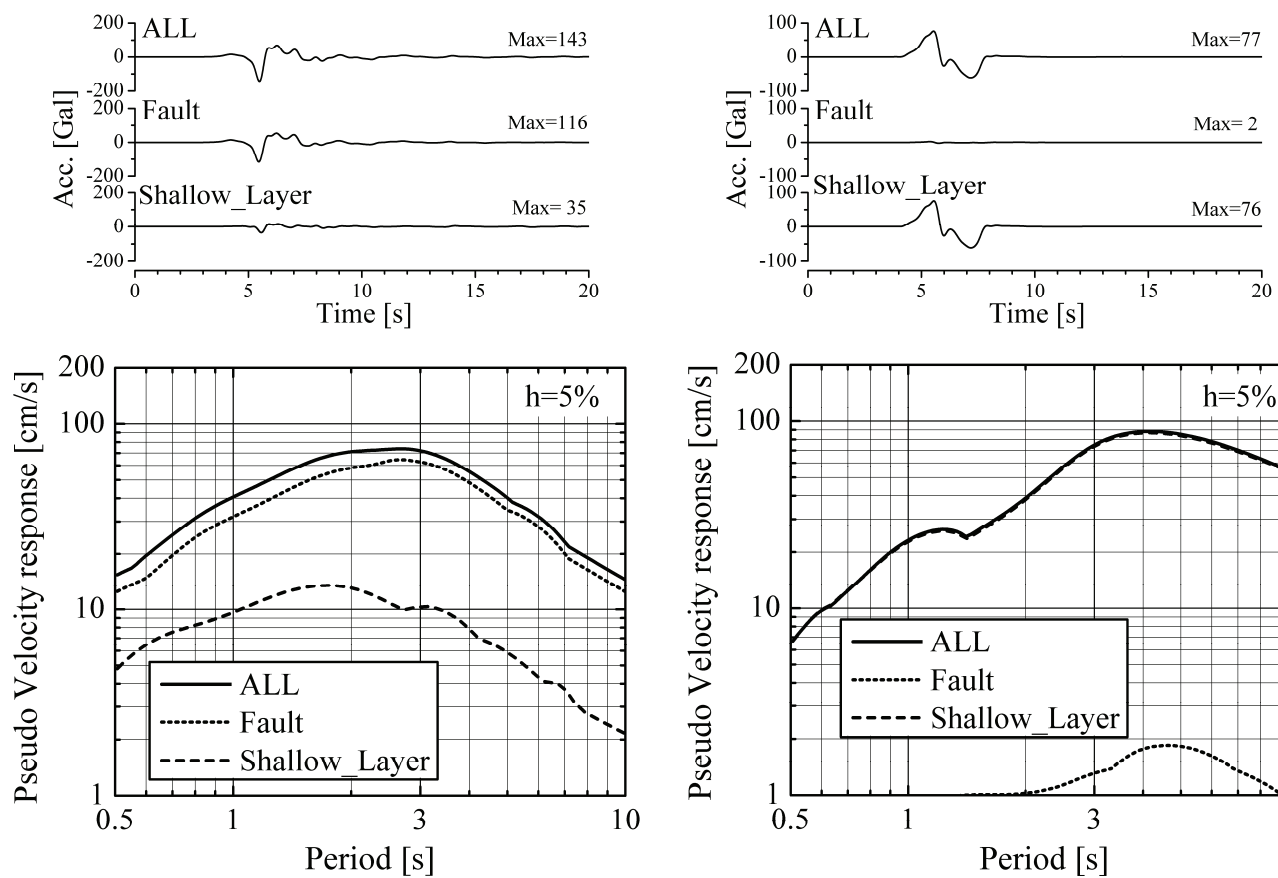

(a) fault normal component

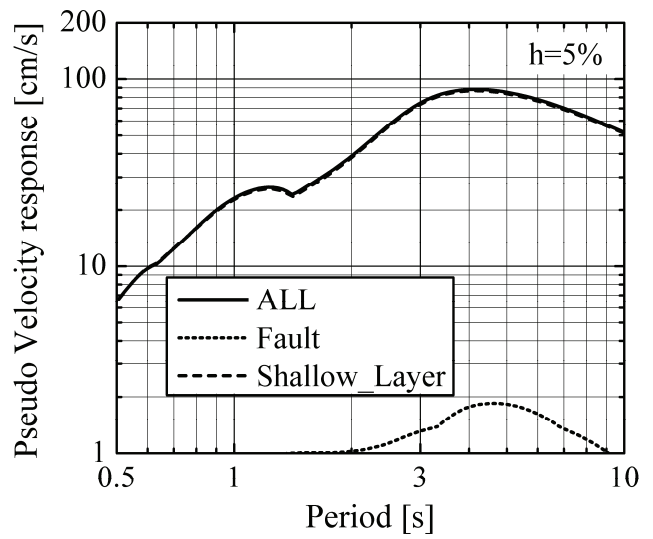

(b) fault parallel component

Figure 13. Comparison seismic waves of case 1(ALL), case 2(Fault), and case 3(Shallow Layer) at the point a1 in Figure 11(fault distance is $50 \mathrm{~m}$ ).
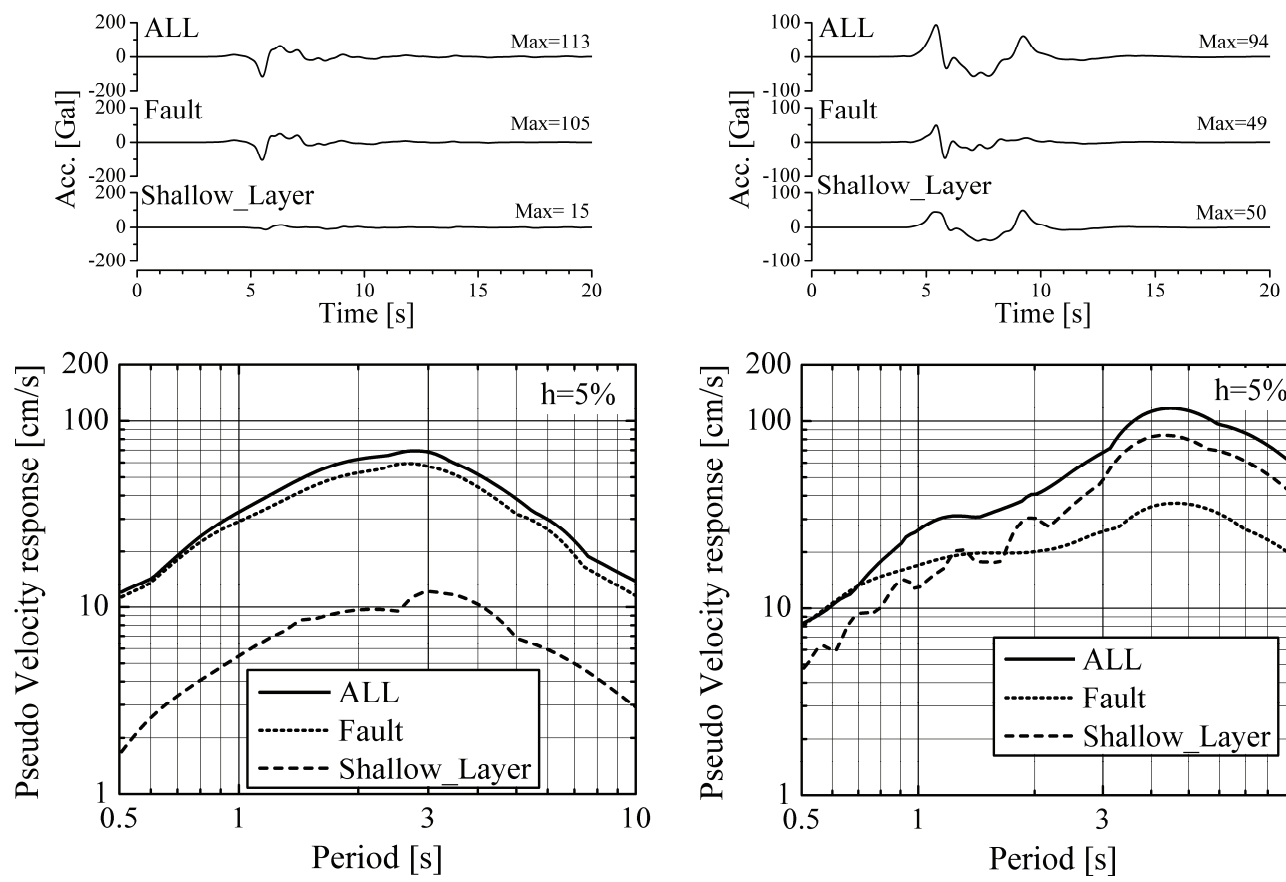

(a) fault normal component

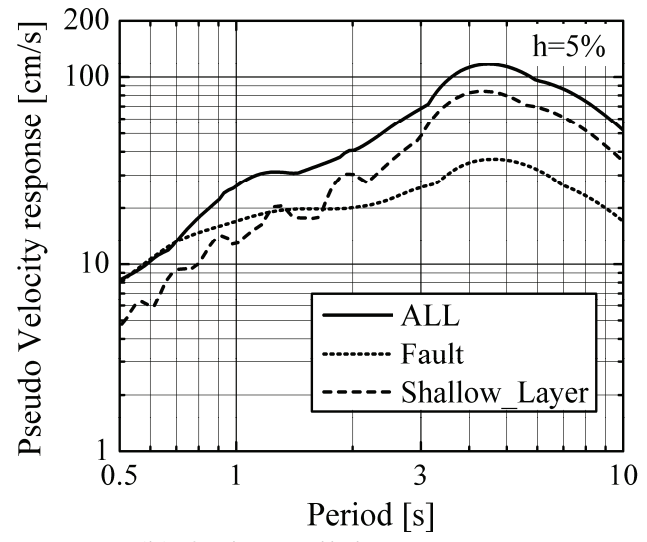

(b) fault parallel component

Figure 14. Comparison seismic waves of case 1(ALL), case 2(Fault), and case 3(Shallow Layer) at the point a5 in Figure 11(fault distance is $1 \mathrm{~km}$ ). 
$23^{\text {rd }}$ Conference on Structural Mechanics in Reactor Technology Manchester, United Kingdom - August 10-14, 2015

Division IV

the soil model, i.e., $\mathrm{Qp}=200$, $\mathrm{Qs}=100$ in the layers shallower than 3-km depth and $\mathrm{Qp}=600$, Qs=300 in the layer deeper than $3 \mathrm{~km}$, to avoid the link effect in FFT. These are also the cause by which the later phases are different subtly.

As the case 2 , we synthesized ground motions by the wave number integration technique using the slip-velocity time functions only in the seismogenic layer (3-18 km depth) obtained by the dynamic fault rupturing simulation. And as the case 3 , we synthesized ground motions using the slip-velocity time function only in the shallow soil (0-3 km depth).

Figure 13 shows the synthesized ground motions at the point 'al' (fault distance is $50 \mathrm{~m}$ ) in Figure 11. Here, (a) shows the fault normal (FN) component and (b) shows the fault parallel (FP) component. And from the top, the figures show the acceleration waves synthesized by the slip-velocity time functions on the entire fault area ('ALL' as case 1), the acceleration waves synthesized by the slip-velocity time functions in the seismogenic layer only ('Fault' as case 2), the acceleration waves synthesized by the slipvelocity time functions in the shallower soil than the seismogenic layer ('Shallow_Layer' as case 3), and the pseudo velocity response spectrum of all the cases calculated from the acceleration waves. As for the FN component (a), the maximum value of the acceleration wave of case 1 (ALL) is $143 \mathrm{Gal}$, and the maximum value of the acceleration wave of case 2 (Fault) is $116 \mathrm{Gal}$. And each maximum values of the pseudo velocity response of these cases are 73.7 kine and 64.5 kine. The latter is about $90 \%$ the former, and this indicates that the influence of the seismic wave radiated from the shallower soil than the seismogenic layer is small in FN component in the region close to the vertical strike-slip fault. And the result of FP component (b) indicates that the pseudo velocity response spectra are smaller than those of the FN component in the period range of 0.5-3 seconds, and that the seismic wave of ALL in the region close to the fault consists of the seismic wave radiated from the shallow layer. Furthermore, the results of other synthesis points at the fault distance less than $0.5 \mathrm{~km} \mathrm{(a2} \mathrm{to} \mathrm{a4,} \mathrm{b1} \mathrm{to} \mathrm{b4} \mathrm{and} \mathrm{c1} \mathrm{to} \mathrm{c4} \mathrm{in} \mathrm{Figure} \mathrm{11)}$ were also similar to Figure 13.

On the other hand, Figure 14 shows the result of point a5 (in Figure 11; fault distance is $1 \mathrm{~km}$ ). The result of the FN component (a) shows that almost no seismic wave radiated from the shallow soil (Shallow Layer) is included in the seismic wave radiated from the entire fault (ALL). And, the result of the FP component (b) shows that the pseudo velocity response spectra of the seismic wave radiated from the entire fault (ALL) are smaller than those of the FN component in the period range of 0.5-3 seconds. And, the result of the FP component, the seismic wave radiated from the seismogenic layer (Fault) becomes as much as the seismic wave radiated from the shallow soil (Shallow Layer).

\section{CONCLUSIONS}

We investigated the influence of the rupture of the shallow soil to the ground motions in the region close to a vertical strike-slip fault, by synthesizing seismic waves by the wave-number integration technique, using the slip-velocity time functions obtained in the dynamic fault rupturing simulation. As results, the following three points were revealed about the ground motions in the region close to the surface fault trace:

1) the fault normal component is larger than the fault parallel component in the period range of $0.5-3$ seconds,

2) as for the fault normal component, contribution from the seismogenic layer is about $90 \%$,

3 ) as for the fault parallel component, contribution from the shallower soil than the seismogenic layer is about $100 \%$.

We are planning to carry out the same examination about the reverse fault.

\section{ACKNOWLEDGMENTS}

This study is some parts of the results of the research project by Nuclear Regulatory Agency, Japan, in the fiscal year of 2013. We appreciate Prof. Emeritus Kojiro Irikura at Kyoto University, Prof. Katsuhiro Kamae at Kyoto University, Prof. Takao Kagawa at Tottori University, Dr. Hiroyuki Fujiwara 
$23^{\text {rd }}$ Conference on Structural Mechanics in Reactor Technology Manchester, United Kingdom - August 10-14, 2015

Division IV

at National Research Institute for Earth Science and Disaster Prevention, Dr. Yoko Kase at Advanced Industrial Science and Technology, Dr. Paul Somerville at URS, and Dr. Arben Pitarka at Lawrence Livermore National Institute for their useful suggestions and discussions.

\section{REFERENCES}

Dan, K., Watanabe, M., Sato, T. and Ishii, T. (2001). Short-period source spectra inferred from variableslip rupture models and modeling of earthquake faults for strong motion prediction by semiempirical method, Journal of Structural and Construction Engineering, No. 545, pp. 51-62 (in Japanese with English abstract).

Hisada, Y. (1994). An efficient method for computing Green's functions for a layered half-space with sources and receivers at close depths, Bulletin of the Seismological Society of America, Vol. 84, No. 4, pp. 1456-1472.

Irie, K., Dan, K., Ikutama, S. and Irikura, K. (2010). Modeling of dynamic fault rupturing constrained by empirical relations among fault parameters of surface and subsurface faults - toward improvement of kinematic fault model for predicting strong ground motions -, Journal of Structural and Construction Engineering. Architectural Institute of Japan, Vol. 75, No. 657, pp. 1965-1974 (in Japanese with English abstract).

Irikura, K. and Miyake, H. (2001). Prediction of strong ground motions for scenario earthquakes, Journal of Geography, Vol. 110, pp. 849-875 (in Japanese with English abstract).

Ito, K. (1999). Seismogenic layer, reflective lower crust, surface heat flow and large inland earthquakes, Tectonophysics, Vol. 306, pp. 423-433.

Kagawa, T., Irikura, K. and Somerville, P. G. (2004). Differences in ground motion and fault rupture process between the surface and buried rupture earthquakes, Earth, Planets and Space, Vol. 56, pp. 3-14.

Matsuda, T. (1975). Magnitude and recurrence interval of earthquake from a fault, Zisin, Second Series, Vol. 28, No. 3, pp. 269-283 (in Japanese with English abstract).

Matsushima, S. and Kawase, H. (2006). Re-evaluation of near source ground motion and damage belt of the Hyogo-ken Nanbu earthquake of 1995, Summaries of Technical Papers of Annual Meeting Architectural Institute of Japan 2006, B-2, Structures II, pp. 271-272. (in Japanese).

Nuclear Regulation Authority. (2013). Review guide related to design basis seismic motions and seismic design policy, (in Japanese).

Pitarka, A. and Dalguer, L. A. (2003): Estimation of dynamic stress parameters of the 1992 Landers earthquake, EOS Transactions, American Geophysical Union, Vol. 84, No. 46, Fall Meeting Supplement, Abstract, S52A-0109.

Pitarka, A. (2005). Rupture dynamics of the 1989 Loma Prieta earthquake, Seismological Research Letters, Vol. 76, No. 2, p. 252.

Pitarka, A., Day, S. and Dalguer, L. A. (2005). Investigation of the cause of difference in ground motion between surface and subsurface faulting based on dynamic rupture modeling, AGU Chapman Conference on Radiated Energy and the Physics of Earthquake Faulting, Portland, Maine, Abstract.

Scholz, C. H. (2002). The Mechanics of Earthquakes and Faulting, Second Edition, Cambridge University Press, pp. 201-202.

$\mathrm{Si}, \mathrm{H}$. and Midorikawa, S. (1999). New attenuation relationships for peak ground acceleration and velocity considering effects of fault type and site condition, Journal of the Structural and Construction Engineering, No. 523, pp. 63-70 (in Japanese with English abstract).

Somerville, P., Irikura, K., Graves, R., Sawada, S., Wald, D., Abrahamson, N., Iwasaki, Y., Kagawa, T., Smith, N., and Kowada, A. (1999). Characterizing crustal earthquake slip models for the prediction of strong ground motion, Seismological Research Letters, Vol. 70, No. 1, pp. 59-80.

Stirling, M., Rhoades, D. and Berryman, K. (2002). Comparison of earthquake scaling relations derived from data of the instrumental and preinstrumental era. Bulletin of the Seismological Society of America, 92, 812-830. 